\title{
CFD Code Calibration and Inlet-Fairing Effects On a 3D Hypersonic Powered-Simulation Model
}

\author{
Lawrence D. Huebner* \\ NASA Langley Research Center \\ Hampton, Virginia \\ Kenneth E. Tatum** \\ Lockheed Engineering \& Sciences Co. \\ Hampton, Virginia
}

\begin{abstract}
A three-dimensional (3D) computational study has been performed addressing issues related to the wind tunnel testing of a hypersonic powered-simulation model. The study consisted of three objectives. The first objective was to calibrate a state-of-the-art computational fluid dynamics (CFD) code in its ability to predict hypersonic powered-simulation flows by comparing CFD solutions with experimental surface pressure data. Aftbody lower surface pressures were well predicted, but lower surface wing pressures were less accurately predicted. The second objective was to determine the 3D effects on the aftbody created by fairing over the inlet; this was accomplished by comparing the CFD solutions of two closed-inlet powered configurations with a flowing-inlet powered configuration. Although results at four freestream Mach numbers indicate that the exhaust plume tends to isolate the aftbody surface from most forebody flowfield differences, a smooth inlet fairing provides the least aftbody force and moment variation compared to a flowing inlet. The final objective was to predict and understand the $3 \mathrm{D}$ characteristics of exhaust plume development at selected points on a representative flight path. Results showed a dramatic effect of plume expansion onto the wings as the freestream Mach number and corresponding nozzle pressure ratio are increased.
\end{abstract}

\begin{tabular}{ll} 
& \multicolumn{1}{c}{ Nomenclature } \\
$\mathrm{M}$ & Mach number \\
$\mathrm{NPR}$ & nozzle pressure ratio, $\mathrm{p}_{\mathrm{t}, \mathrm{jet}} / \mathrm{p}_{\infty}$ \\
$\mathrm{p}$ & pressure, $\mathrm{Pa}$ \\
$\mathrm{Re}$ & Reynolds number, $1 / \mathrm{m}$ \\
$\mathrm{T}$ & temperature, $\mathrm{K}$ \\
$\mathrm{X}_{\text {aftbody }}$ & aftbody length from cowl trailing edge to body \\
& $\quad$ trailing edge \\
$\mathrm{X}, \mathrm{y}, \mathrm{z}$ & streamwise, spanwise, and vertical coordinates \\
$\mathrm{Y}_{\text {aftbody }}$ & model fuselage maximum semispan \\
$\alpha$ & angle of attack, degrees \\
$\rho$ & density, kg/m \\
Subscripts & \\
\hline$\infty$ & freestream conditions \\
throat & conditions at the internal nozzle throat \\
t, jet & jet total conditions \\
wall & conditions at a solid wall boundary
\end{tabular}

\footnotetext{
*Aerospace Engineer, Hypersonics Group Leader, Supersonic/ Hypersonic Aerodynamics Branch, Applied Aerodynamics Division, AIAA Senior Member

**Aerodynamics Staff Engineer, Aeronautics Department, AIAA Senior Member
}

\section{Introduction}

The National Aero-Space Plane (NASP) community has a critical need to accurately determine the aero-propulsive effects and performance of hypersonic airbreathing configurations under powered conditions. To accomplish this, a wind tunnel model is typically designed and fabricated with some method of simulating the powered effects of scramjet combustion. One such method uses a non-combusting gas to simulate some of the major scramjet exhaust properties. This simulant gas is routed from an external supply and through the model support structure (strut or sting) to the model. The exhaust flow is then established in the plenum chamber of the model and expanded out through an appropriately-designed nozzle.

Two methods to handle the inlet flow are to ingest the flow into the inlet or to design a geometrical inlet fairing to divert the oncoming inlet flow around the inlet plane. Due to the relatively small scale of model that can be tested in typical hypersonic wind tunnels, as well as the short enginemodule lengths employed on these models, it is not possible to use the flow-ingesting method which requires both capturing the inlet flow and producing the simulated exhaust flow. There is simply not enough volume to process both the inlet and exhaust flow. The inlet flow would have to either pass directly through the model or be evacuated out of the model. The second approach for treating the inlet flow is to employ a fairing from the forebody to the cowl leading edge and divert the inlet flow around the outside of the model. However, such forebody geometry changes affect the flowfield structure in the forebody region and may affect the aftbody/ exhaust interactions as well.

This computational study consists of three parts. First a three-dimensional (3D) calibration is made of the ability to predict these types of hypersonic powered-simulation flows using a state-of-the-art computational fluid dynamics (CFD) code by comparing these solutions with experimental surface pressure data. The second objective is to determine the $3 \mathrm{D}$ effects of inlet fairing on the aftbody. The inlet-fairing study is an attempt to ascertain the influence of these non-realistic (but necessary for wind tunnel testing) forebody configurations on the powered aftbody and wings for four different freestream Mach numbers and associated nozzle pressure ratios. The final objective is to predict and understand the 3D characteristics of exhaust plume development at selected points on a representative flight path. An understanding of the extent of the plume boundaries for a series of freestream Mach numbers and nozzle pressure ratios is presented.

Copyright (C) 1993 by the American Institute of Aeronautics and Astronaūtics, Inc. No copyright is asserted in the United States under Title 17, U.S. Code. The U.S. Government has a royalty-free license to exercise all rights under the copyright claimed herein for Governmental purposes. All other rights are reserved by the copyright owner. 


\section{Computational Code}

The objectives of this study were performed using the General Aerodynamic Simulation Program (GASP), originally developed at Virginia Polytechnic Institute and State University by Dr. Robert W. Walters ${ }^{1}$. Since this research began, a new version of GASP has been released, as discussed in reference 2. The GASP code solves the integral form of the Reynolds-Averaged Navier-Stokes equations and its subsets, namely, the Euler, parabolized Navier-Stokes (PNS), and thin-layer Navier-Stokes (TLNS) equations. GASP is a fully three-dimensional (3D) code employing structured multi-block grids and a variety of computational, transport, thermodynamic, and chemistry models. The first objective (code calibration) was performed with GASP version 1.2, whereas the inlet-fairing and plume-characterization studies were performed with GASP version 2.0. The new version reduces the convergence time and memory required to perform a given computation; the accuracy of the solutions was equally good for both versions on identical problems.

\section{Code Calibration Study}

Before any CFD code can be used as an analysis tool, code calibration is essential for the types of flows of interest to provide a level of confidence in the ability of the code to accurately predict the fluid dynamics of the problem. Previous studies using GASP have shown that it has the ability to accurately predict complex three-dimensional hypersonic flows past configurations representative of NASP forebodies $^{3-5}$, as well as the two-dimensional powered effects on model aftbodies ${ }^{6,7}$. In the current study, code calibration will be made using a three-dimensional powered aftbody model. Surface pressure data was obtained on a wind tunnel model $^{8}$ and will be used to compare with the CFD solutions.

\section{Geometry}

The computational surface used in this part of the study (Fig. 1) was the powered Test Technique Demonstrator (TTD) model, as tested under simulated powered conditions in the NASA Langley 20-Inch Mach 6 Wind Tunnel. The geometry consists of a forebody with a faired-over inlet to divert the oncoming flow around the engine package, an internal nozzle designed to provide a combustor exit Mach number of about 1.8 for exhaust simulation, and an aftbody including a wing at an incidence angle of -1.5 degrees. Computational solutions were performed on a semispan

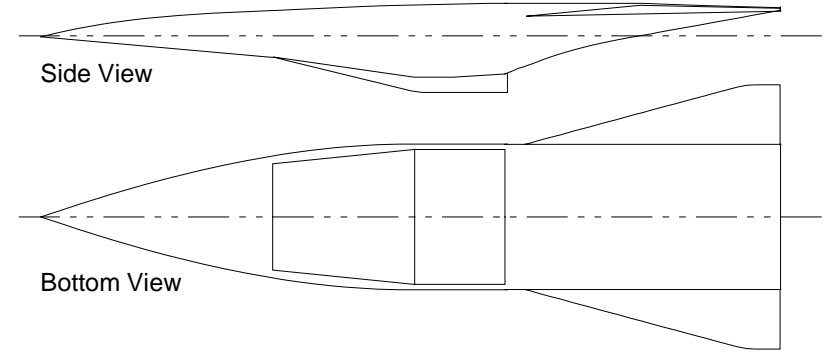

Fig. 1. Powered Test Technique Demonstrator Model model to conserve computational resources. PNS (spacemarching) solutions were initiated with freestream reference conditions at the model nose for the external flow and with appropriate conditions near the nozzle throat for the internal flow. The external and internal solutions were then merged at the cowl trailing edge and space marched downstream to provide the solution on the aftbody portion of the model. The total number of computational cells for this configuration (clustered near solid surfaces) is just under one million, and they are distributed in the following way: forebody-184,320 cells, internal nozzle--239,360 cells, and aftbody with wing--573,440 cells.

\section{Physical Conditions for Computational Solutions}

The calibration study was performed using the same conditions that were employed in testing the powered TTD in the 20-Inch Mach 6 Wind Tunnel. These consisted of one set of external flow conditions and two sets of internal flow conditions. The internal conditions corresponded to the two different non-combusting simulant exhaust gases employed. The first is a mixture of tetraflouromethane $\left(\mathrm{CF}_{4}\right)$ and argon (Ar), a thermally perfect gas that approximately matches the ratio of specific heats of the hot hydrogen/air combustion products of the scramjet exhaust but at much lower temperatures. The other exhaust gas is air, heated only to prohibit liquefaction upon expansion into the aftbody region. Even though air is calorically perfect (and thus does not provide the appropriate ratio of specific heats), it was used as an exhaust gas for economy reasons. The external flow was assumed to be perfect gas air. Specific conditions for each computation are shown in Tables I and II. The internal and external flows are related through a single parameter, nozzle pressure ratio (NPR), defined as the ratio of the jet total pressure to the freestream pressure (NPR $\left.=\mathrm{p}_{\mathrm{t}, \mathrm{jet}} / \mathrm{p}_{\infty}\right)$. For the two exhaust-gas cases discussed above, $\mathrm{NPR}_{\text {air }}$ is about 1500 , while $\mathrm{NPR}_{\mathrm{CF}_{4} \mathrm{Ar}}$ is about 1100 . Because the different gases flow through specificallydesigned nozzles, the physical conditions presented above result in the same internal static pressure at the cowl trailing edge, $\mathrm{p}_{4}$, of about $16.5 \mathrm{kPa}$.

Table I. External Physical Conditions for CFD Solutions.

$\begin{array}{ll}\mathrm{M}_{\infty} & 5.87 \\ \mathrm{Re}_{\infty} & 3.28 \times 10^{6} / \mathrm{m} \\ \alpha, \text { degrees } & 0 \\ \mathrm{~T}_{\infty}, \mathrm{K} & 56.54 \\ \mathrm{p}_{\infty}, \mathrm{Pa} & 255.713 \\ \rho_{\infty}, \mathrm{kg} / \mathrm{m}^{3} & 0.015755\end{array}$

Table II. Internal Physical Conditions for CFD Solutions.

\begin{tabular}{lcc} 
Parameter & Air Exhaust & $\mathrm{CF}_{4}$-Ar Exhaust \\
\hline $\mathrm{M}_{\text {throat }}$ & 1.034 & 1.031 \\
$\mathrm{p}_{\text {t,jet }}, \mathrm{kPa}$ & 382.969 & 283.374 \\
$\mathrm{~T}_{\text {throat }}, \mathrm{K}$ & 458.33 & 348.5 \\
$\mathrm{p}_{\text {throat }}, \mathrm{kPa}$ & 193.854 & 155.317 \\
$\rho_{\text {throat }}, \mathrm{kg} / \mathrm{m}^{3}$ & 1.47352 & 3.9447
\end{tabular}




\section{$\underline{\text { CFD Solution Issues }}$}

The viscous boundary layers for all solutions were assumed to be laminar. In the streamwise direction, full fluxes were employed using a Van Albeda-type smooth limiter and second-order, fully-upwind spatial discretization. In the circumferential direction, Van Leer's flux vector splitting was used with the Spekraize-Venkat limiter and third-order, upwind-biased spatial discretization. In the body-normal direction, Roe's flux difference splitting was used with the Spekraize-Venkat limiter and third-order, upwind-biased spatial discretization ${ }^{1}$. In addition to the initial conditions imposed on the first solution plane (on the forebody and the internal nozzle), a no-slip, fixed-wall-temperature boundary condition was imposed on all body surfaces $\left(T_{\text {wall }}=305.33\right.$ $\mathrm{K}$ ), while first-order extrapolation boundary conditions were imposed on the outer grid boundary. The downstream boundary was ascribed a second-order extrapolation boundary condition, while the upper and lower center-planes of the grid had an $\mathrm{x}-\mathrm{Z}$ symmetry boundary condition imposed. The grids were clustered near solid surfaces such that the average value of the inner law variable ${ }^{9}$ at the first computational cell center away from the body was about three, with some localized regions that were as high as twelve (on the wing leading edge). Marching plane residuals were reduced five orders of magnitude for the first three planes of the external and internal flows, providing a good establishment of the solution features. The remainder of the marching planes were converged to four orders of magnitude residual reduction since this was adequate to stabilize the surface pressures and other flowfield features of interest ${ }^{10}$.

\section{CFD Code Calibration Results}

A direct comparison of surface pressures from CFD solutions and wind tunnel experimental data is presented to address the capability of the CFD code to predict these types of flows. Figure 2 shows pressure comparisons along three streamwise rows and one spanwise row on the aftbody. In each plot, the abscissa has been nondimensionalized with the

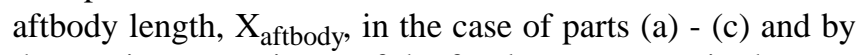
the maximum semispan of the fuselage, $\mathrm{Y}_{\mathrm{aftbody}}$, in the case of part (d). Symbols denote the experimental pressures, and lines denote the computational solution. Squares and dashed lines indicate air-exhaust simulation, while circles and solid lines indicate $\mathrm{CF}_{4}-\mathrm{Ar}$ exhaust simulation. Figure 2a presents pressure on the lower aftbody centerline as a function of streamwise location (data row A). The initial compressions shown in the CFD solutions are caused by a centerline nozzle strut that was modeled in both the experimental and computational internal nozzles. (The cowl, strut, and sidewalls all had sharp trailing edges at the internal nozzle exit plane.) As can be seen, the computational predictions agree well with the experimental pressure data, including the increased centerline pressures caused by the air exhaust. Figure $2 b$ shows streamwise pressure comparisons near the mid-semispan fuselage location (data row B). Again, the comparisons are considered good, except for the slight over-prediction of the computed pressures just beyond the cowl trailing edge.

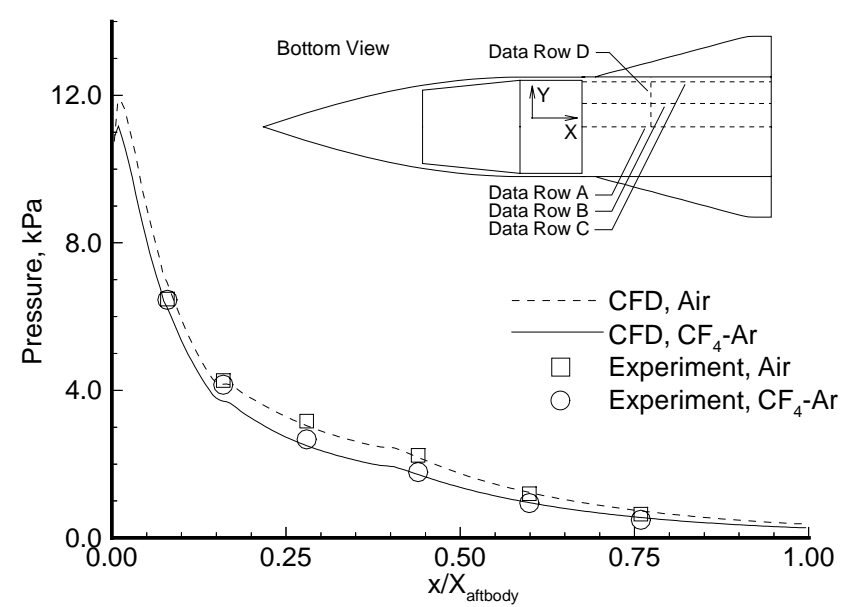

(a) Data row $A$

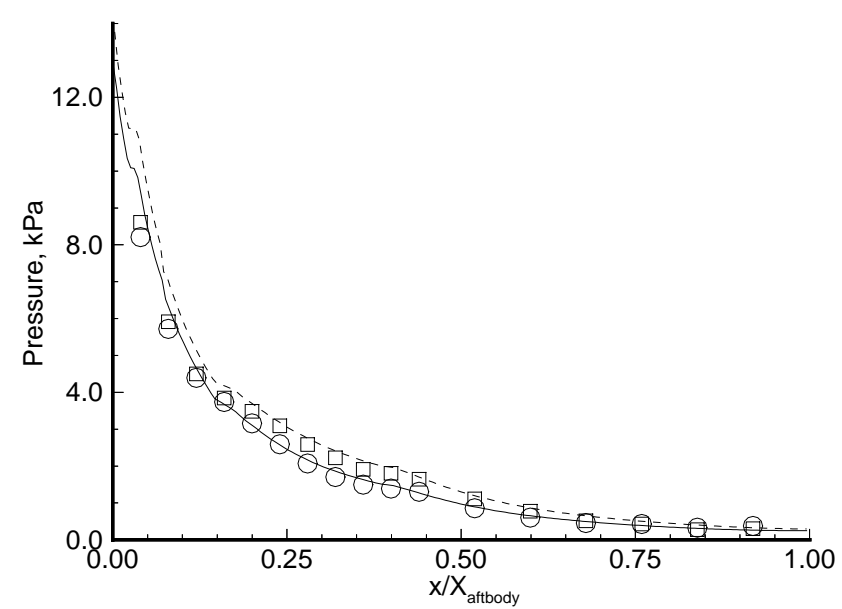

(a) Data row B

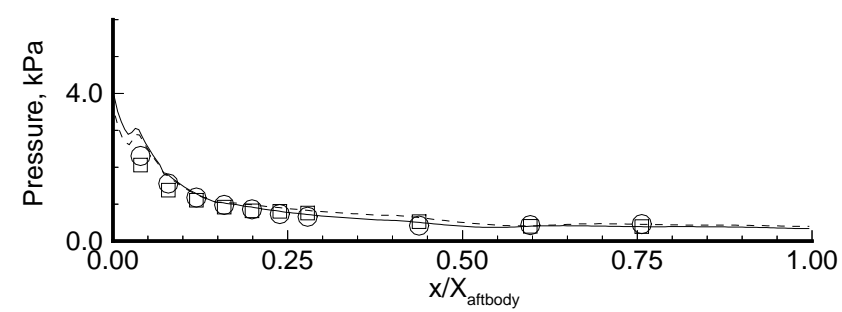

(c) Data row $C$

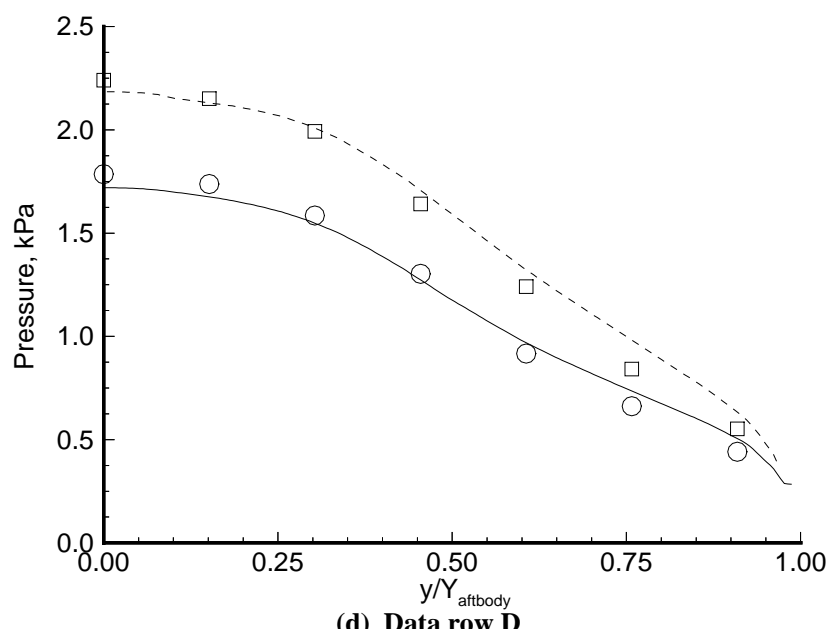

Fig. 2. Aftbody lower surface pressure comparisons, $M_{\infty}=5.87$, $\operatorname{Re}_{\infty}=3.28 \times 10^{6} / \mathrm{m}, p_{4} \sim 16.5 \mathrm{kPa}$. 
Agreement improves further downstream. Figure $2 \mathrm{c}$ shows the significant decrease of pressure near the maximum semispan of the fuselage (data row $\mathrm{C}$ ). There is still good agreement in the computational solutions and experimental data, but there is a noticeable difference in trends at various spanwise locations which is evident in both the computational and experimental results. Near the cowl trailing edge, the $\mathrm{CF}_{4}$ - $\mathrm{Ar}$ exhaust is at a higher pressure than the air exhaust, indicating a stronger lateral effect of the $\mathrm{CF}_{4}$-Ar exhaust.

Figure $2 \mathrm{~d}$ shows the lower surface pressures along a spanwise row of orifices about midway down the aftbody. Model centerline is at the left and the fuselage edge is at the right. The three-dimensional lateral relief is seen by a decrease in pressure moving away from the centerline. Good agreement between computational and experimental results and the air exhaust exhibiting a higher overall pressure than $\mathrm{CF}_{4}$ - $\mathrm{Ar}$ are seen as consistent trends in the above results. The one discrepancy in the computational and experimental results is that the computed lateral pressure gradient is slightly smaller than that observed in the experimental data.

Figure 3 presents pressure comparisons at four spanwise rows on the lower wing while the model is under powered conditions. The plots extend from the wing root to the local wing tip, and the abscissa has been normalized by the fuselage maximum semispan. Aside from there being limited experimental data, Fig. 3a shows a poor comparison of computational and experimental pressures, exemplified by the computational over-prediction at the wing root. Note that wing pressures are all relatively small $(\sim 700 \mathrm{~Pa})$ causing the differences to appear more significant than they are. Agreement of computational and experimental results improves slightly farther downstream (Fig. 3b), but the overprediction of pressures at the wing root are still present. Furthermore, the trend of higher pressures for air exhaust is inconsistent with the experimental data. Improved agreement between computational and experimental pressure results on the wing is shown in Fig. 3c, at a location about 75 percent down the aftbody. The computational results continue to over-predict the lower surface pressures near the wing root, but the trends are much better predicted. At this location, both measured and predicted results show correct trends of higher pressures for the air exhaust as compared to the $\mathrm{CF}_{4}$-Ar exhaust, as well as pressures that increase with spanwise distance. At a streamwise location about $92 \%$ down the aftbody (Fig. 3d), there is much better agreement between computed and measured pressures. Not only are the overall trends in agreement, but the magnitudes are closer. The region for which the CFD over-predicts the pressure has moved outboard of the wing root, indicating a lateral movement of the cause of the discrepancy. This may be due to the fact that either the body has thinned considerably at this streamwise location resulting in a smaller corner-flow region near the wing/fuselage juncture or that a wing leading-edge induced vortex is generated. It is possible that this type of comparison could be improved with computational solutions that predict separated flows better, such as the TLNS equations.

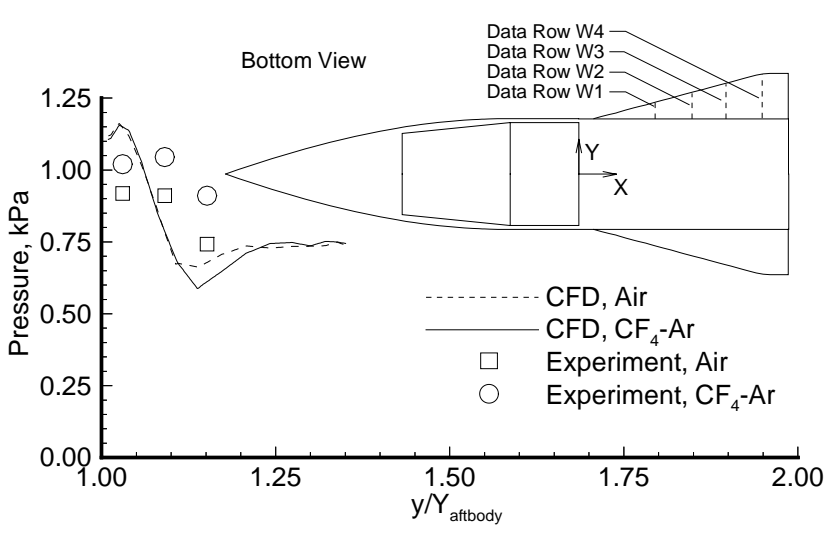

(a) Data row W1

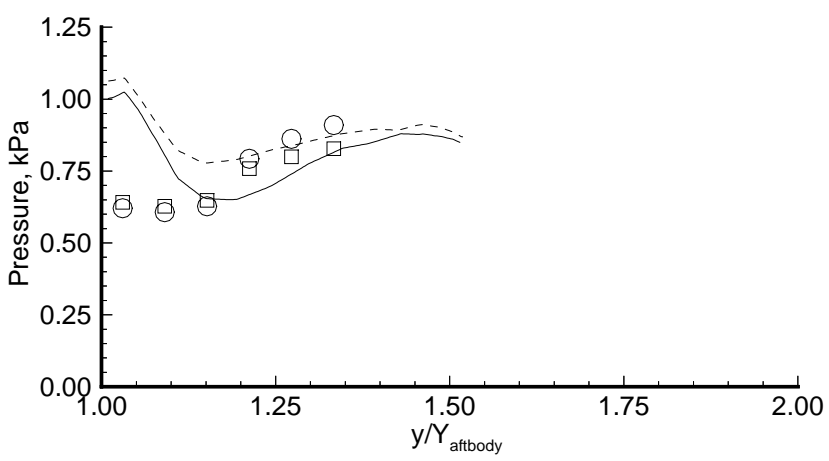

(a) Data row W2

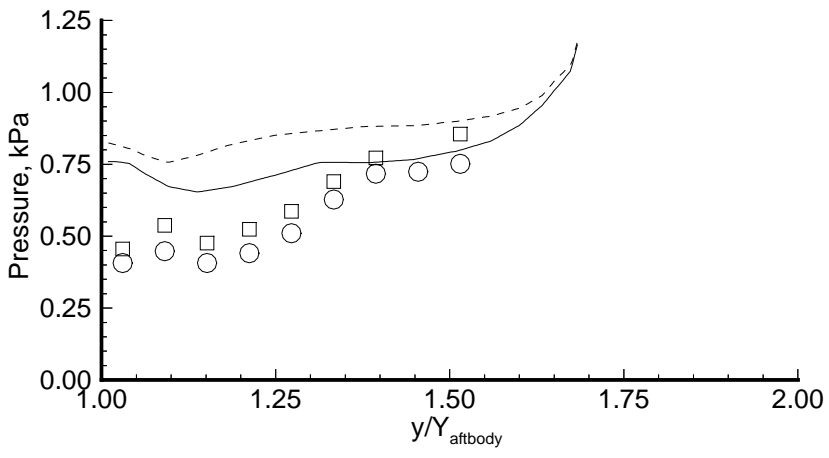

(a) Data row W3

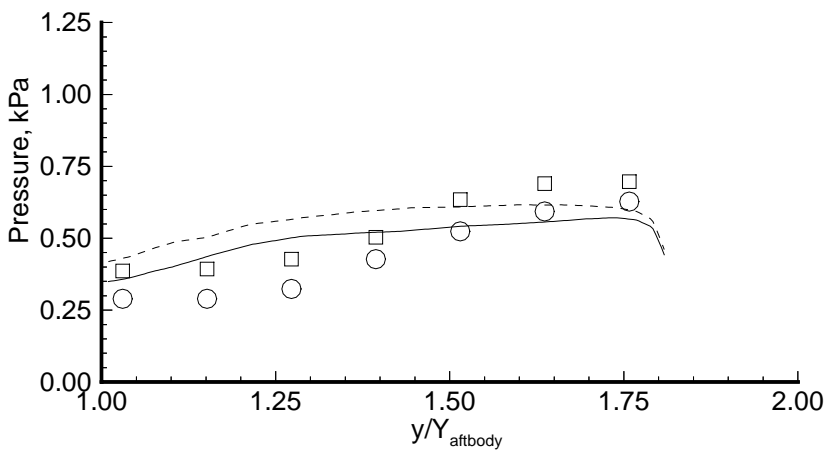

(d) Data row $\mathrm{W4}$

Fig. 3. Wing lower surface pressure comparisons, $M_{\infty}=5.87$, $\operatorname{Re}_{\infty}=3.28 \times 10^{6} / \mathrm{m}, \mathbf{p}_{4} \sim 16.5 \mathrm{kPa}$. 


\section{Inlet-Fairing/Plume Studies}

Having gained some confidence in the code's ability to predict the aftbody surface-pressure effects, the last two paper objectives were undertaken to gain insight into the effects of inlet fairing and plume characteristics on the powered aftbody. The computational effort allowed for the prediction of external flow features for three inlet representations without regard for the ingested "flow" into the inlet. The approach taken was to merge each of the flowfields computed from the three forebody/inlet representations with the same internal nozzle solution for each of the four given freestream Mach numbers. The resulting aftbody solutions then had both the primary plume influence near the body from the internal flow, as well as the differences in external flow resulting from the different forebodies.

Geometry

The three different 3D forebody/inlet representations of interest in the inlet-fairing/plume studies are shown in Fig. 4. The flow-ingested inlet model (Fig. 4a) assumes that there is no spillage and that the external flow beyond the cowl is not influenced by what occurs within the inlet. The last two can be categorized as closed-inlet configurations. The fairedover inlet (Fig. 4b) is a "soft" fairing, beginning at the compression ramp break of the forebody and developing along straight-line rays to the cowl leading edge. This was the initial attempt at minimizing the influence of the fairing on the plume and nozzle. The blocked-off inlet (Fig. 4c) is a "worst-case" fairing, produced by closing off the inlet with a planar surface between the forward extent of the cowl sidewall leading edges. However, it is also of interest because it represents the typical unpowered vehicle entry configura-

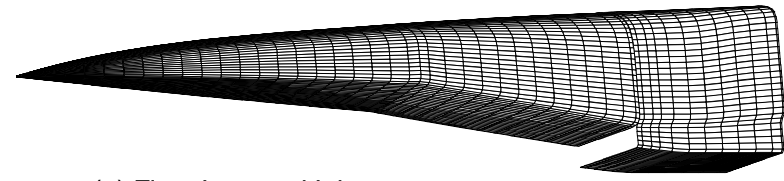

(a) Flow-Ingested Inlet

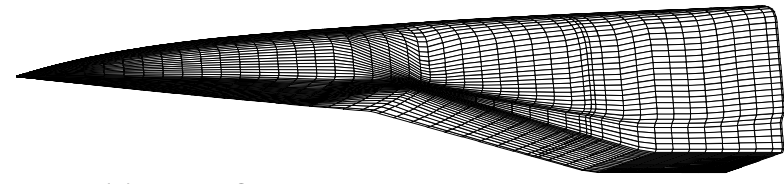

(b) Faired-Over Inlet

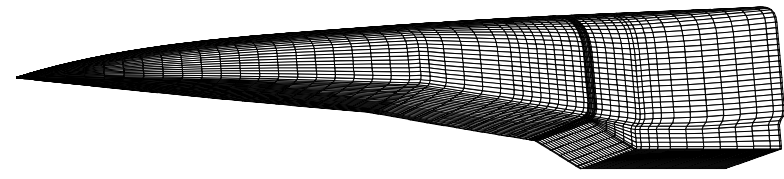

(c) Blocked-Off Inlet

Fig. 4. Computational forebody surface representations. tion. The internal nozzles are contoured to provide appropriate values of exhaust Mach number at the cowl trailing edge, and the aftbody with wings is identical for all simulations.

\section{Physical Conditions for Computational Solutions}

Each complete 3D solution simulating a powered model is comprised of three parts. The external forebody and internal nozzle solutions were computed separately. Then flow information required by GASP to start the aftbody solution was obtained at cell centers of the aftbody grid at the cowl trailing edge by using bilinear interpolation of the external forebody and internal nozzle flow variables computed at the cowl trailing edge.

The physical information needed to generate solutions for four different Mach numbers of interest is provided in Table III. The external flow conditions correspond to a Reynolds number of $6.56 \times 10^{6} / \mathrm{m}$ for the four freestream Mach numbers given, and all cases were performed at $\alpha=0$ degrees. The conditions at the nozzle throat indicate the four different representative NPRs for the four different freestream Mach numbers; realistically appropriate values of NPR are 30, 200, 3,000, and 40,000 for the four nominal freestream Mach numbers of 3.4, 6.0, 10.0, and 14.0, respectively. (The reason the actual freestream Mach numbers in Table III differ from the nominal values stated is because the values used were chosen to correspond to actual test conditions in existing wind tunnels at $\mathrm{Re}_{\infty}=6.56 \times 10^{6} / \mathrm{m}$.) As can be seen from the table, both the external freestream pressure and the internal jet pressure variation with Mach number can be seen in the large extremes in NPR. For this study, the simulant exhaust gas is modeled as a single-species gas with a molecular weight equal to that of the $\mathrm{CF}_{4} \mathrm{Ar}$ mixture discussed in the previous section. The ratio of specific heats was fixed at 1.27, the approximate average value for the varying specific heat ratio in the aftbody region for the actual $\mathrm{CF}_{4} \mathrm{Ar}$ mixture (which is thermally perfect). The computational issues that were addressed in the calibration part of this paper are also imposed on the inlet-fairing/plume studies, including the choice of boundary conditions, limiters, and convergence criteria. However, one difference encountered was that some of the aftbody solutions were computationally stiff, particularly at the high NPRs, and required that the initial few planes be solved with first-order spatial accuracy in the streamwise direction and then recomputed using second-order spatial accuracy.

Table III. Physical Conditions for Inlet-Fairing/Plume Study.

\begin{tabular}{|c|c|c|c|c|}
\hline & Mach 3.4 & Mach 6 & Mach 10 & Mach 14 \\
\hline$M_{\infty}$ & 3.40 & 5.92 & 10.14 & 13.66 \\
\hline NPR & 30 & 200 & 3,000 & 40,000 \\
\hline $\mathrm{T}_{\infty}, \mathrm{K}$ & 102.25 & 55.838 & 49.556 & 50.621 \\
\hline $\mathrm{p}_{\infty}, \mathrm{Pa}$ & 1982.05 & 474.773 & 209.531 & 174.267 \\
\hline$\rho_{\infty}, \mathrm{kg} / \mathrm{m}^{3}$ & $6.756 \times 10^{-2}$ & $2.964 \times 10^{-2}$ & $1.474 \times 10^{-2}$ & $1.200 \times 10^{-2}$ \\
\hline $\mathrm{M}_{\text {throat }}$ & 1.034 & 1.034 & 1.034 & 1.034 \\
\hline $\mathrm{T}_{\text {throat }}, \mathrm{K}$ & 329.934 & 329.934 & 383.337 & 708.611 \\
\hline $\mathrm{p}_{\text {throat }}, \mathrm{kPa}$ & 31.537 & 50.361 & 333.388 & $3,697.1$ \\
\hline$\rho_{\text {throat }}, \mathrm{kg} / \mathrm{m}^{3}$ & 0.74344 & 1.18720 & 6.76431 & 40.5791 \\
\hline
\end{tabular}




\section{Inlet-Fairing Results}

Results of the inlet-fairing study are presented with representative plots of Mach number contours at the model centerline and at aftbody cross planes, aftbody lower surface pressure contours, and relative force and moment data. The flowfield plots are not inclusive of all solutions performed, but highlight the major physical phenomena that are caused by the different forebody representations. The force and moment data does include information from all solutions that were performed.

To illustrate the flowfield differences caused by the different forebody geometries, centerline Mach number comparisons are shown (Fig. 5) for the $\mathrm{M}_{\infty}=5.92, \mathrm{NPR}=200$ condition. As expected, the upper surface flow is basically unaffected by the variation in inlet representation. The effect of the stronger shocks from the faired-over and blocked-off inlet cases is evident, when compared with the flow-ingested inlet solution. Note that, for the blocked-off inlet case, the intersection of the two forebody shocks, one from the compression ramp break and one from the beginning of the blocked inlet, is very near the cowl leading edge, behind which the flow rapidly expands over the surface of the cowl. Also, the cowl boundary layer for the flow-ingested inlet case is much smaller than the other two cases, since the
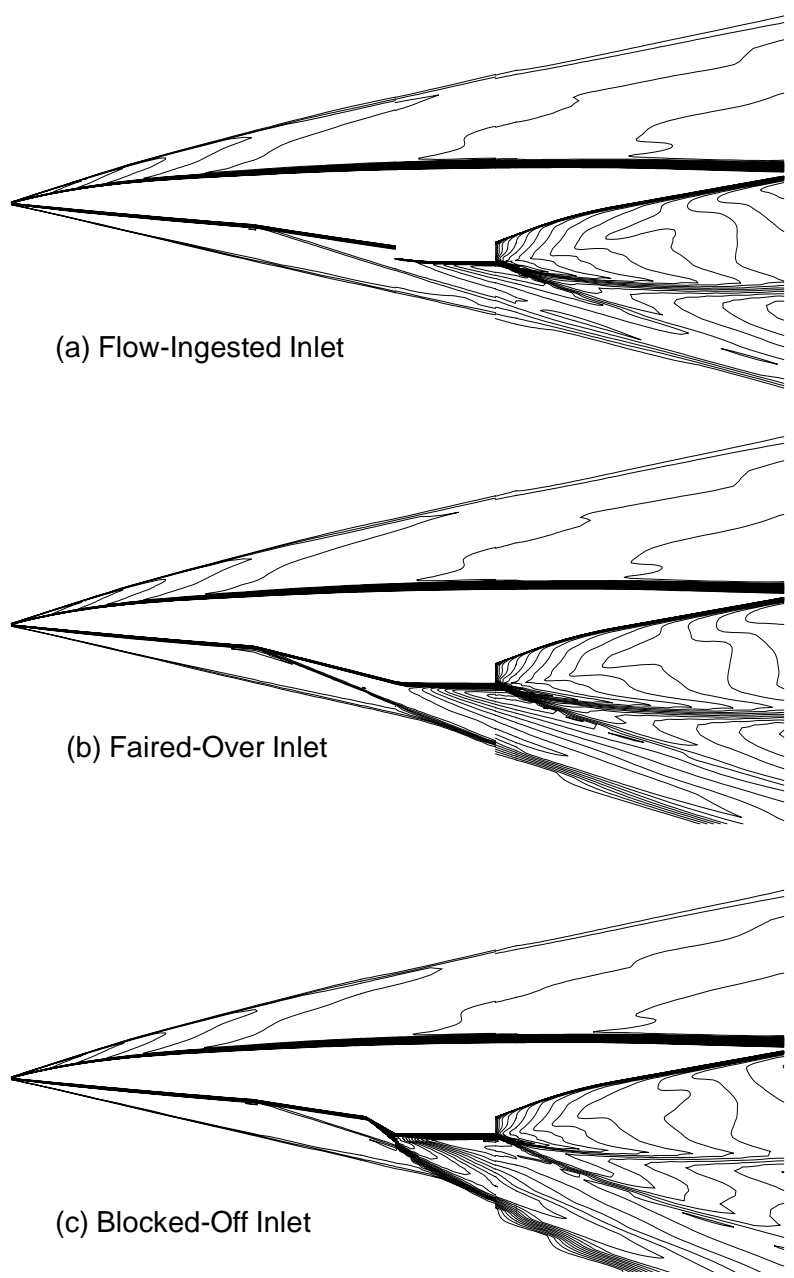

Fig. 5. Centerline Mach number contours, $M_{\infty}=5.92, N P R=200$. boundary layer develops from the cowl leading edge, not the forebody nose as for the faired-over and blocked-off inlet cases. Small differences in Mach number contours within the plume shear layer can be seen, but the actual location of the shear layer is basically unaffected by the different forebody representations.

Figures 6 and 7 present comparisons of flowfield Mach number contours just beyond the cowl trailing edge and at the body trailing edge for each of the three comparative CFD solutions. In Fig. 6, flowfield differences are confined to the external flow, since the internal solutions were identical for each of the three solutions. The stronger shocks for the two closed-inlets (Fig. 6b and 6c) can be seen below the body, along with the fact that the flow between the external shock and the plume does not expand back to the same Mach number as the flow-ingested inlet solution. Furthermore, there is evidence of additional flow structure near the outboard lower corner of the plume flow for the closed-inlet solutions generated by the oncoming flow being diverted around the closedoff inlets. Figure 7 shows that at this value of NPR the plume does not expand much out over the wings and stays almost rectangular in shape at the end of the body. The strength of the lower part of the shear layer is diminished for the blocked-off inlet as seen by fewer Mach number contours which make it up. However, the boundary layer and flow within the plume are nearly identical for the three cases, indicating that the plume tends to isolate the aftbody lower surface from the external forebody flow features.

Comparisons of pressure contours on the lower surface of the aftbody and wing are shown in Fig. 8 for the $\mathrm{M}_{\infty}=10.14$, NPR $=3,000$ condition. Upper surface pressure contours on the aftbody were virtually identical for all three cases and thus are not presented here. This indicates that the effect of the plume is restricted to the lower surface for the conditions simulated. Figure 8 is presented as pressure ratio comparisons, where the local surface pressure has been normalized by the freestream pressure at this condition. Close examination of the two closed-inlet solutions shows very small differences in pressure on the lower surface of the aftbody and wing compared with the flow-ingested inlet solution.

Figure 9 presents the relative aftbody force and moment data as determined by pressure area integration on the aftbody, i.e., that part of the configuration downstream of the cowl trailing edge. Each part of Fig. 9 shows two kinds of information, the effect of inlet fairing throughout the Mach number range of interest and the contributions of the aerodynamic and propulsive surfaces on the aftbody. The shaded area in the sketch on Fig. 9a defines the extent of the propulsive surface. The aerodynamic surface is the remainder of the aftbody, including the upper surface, wings, and aftbody sidewalls. Each of the three force and moment components presented has been nondimensionalized by their respective total aftbody force or moment value from the flow-ingested inlet solutions at each appropriate freestream Mach number. Thus, the total relative force and moment values for the 


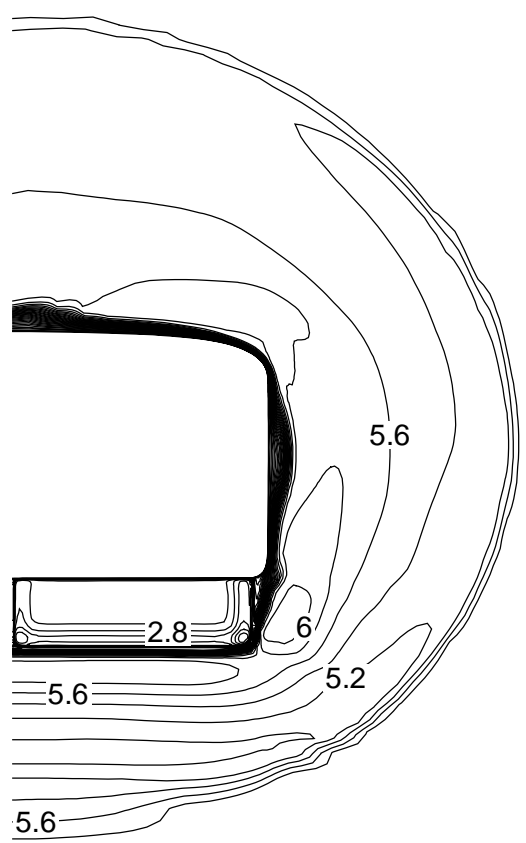

(a) Flow-Ingested Inlet

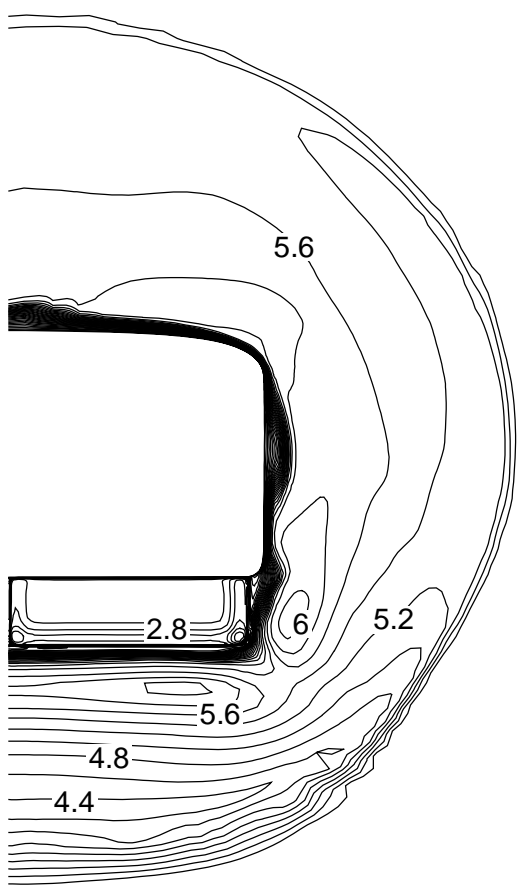

(b) Faired-Over Inlet

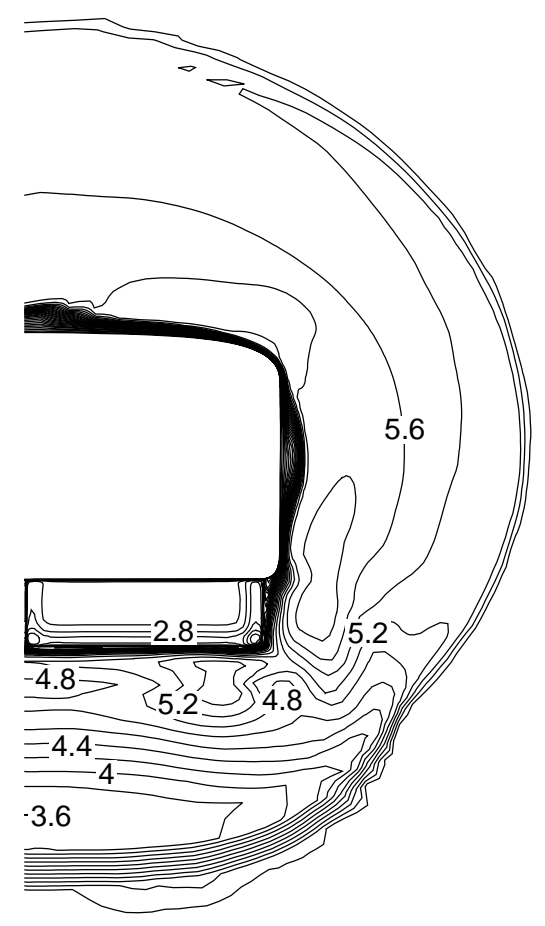

(c) Blocked-Off Inlet

Fig. 6. Mach number comparisons, just beyond cowl trailing edge, $M_{\infty}=5.92, N P R=200$.

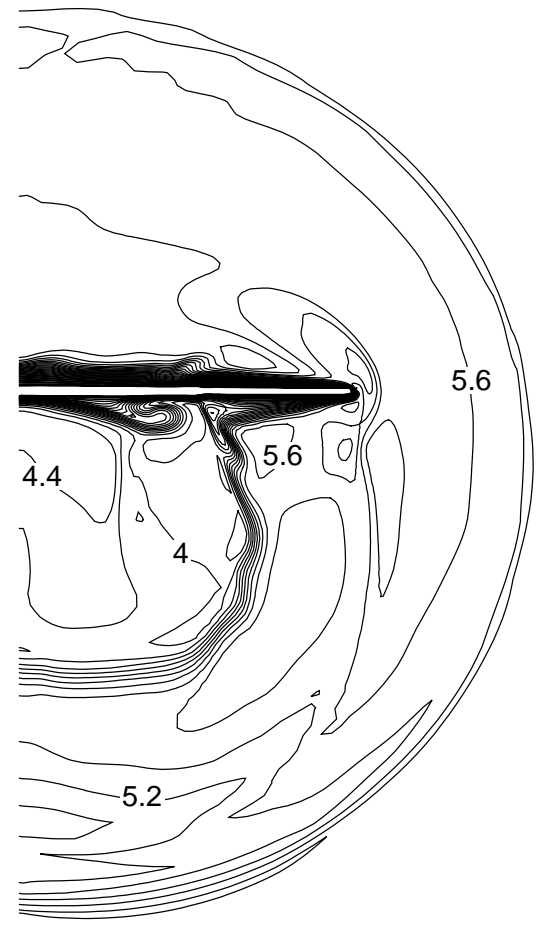

(a) Flow-Ingested Inlet

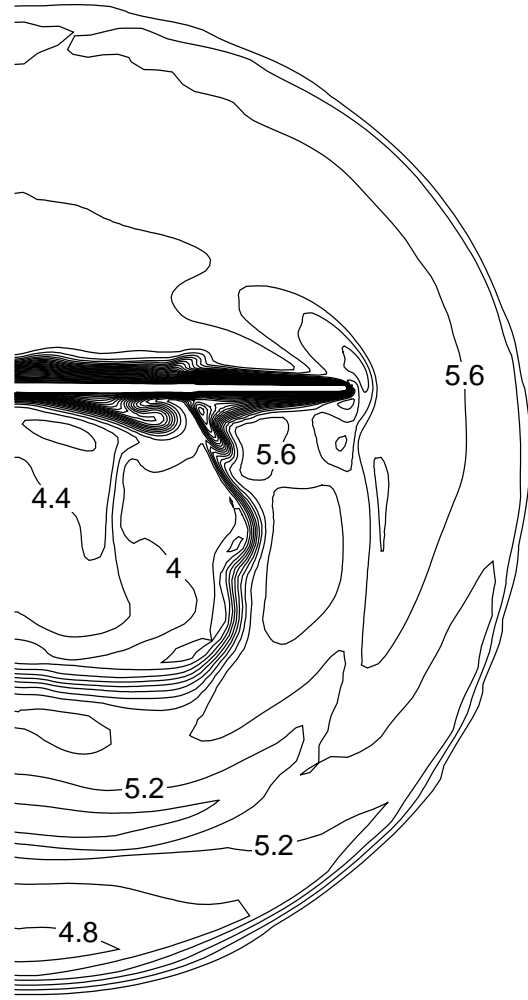

(b) Faired-Over Inlet

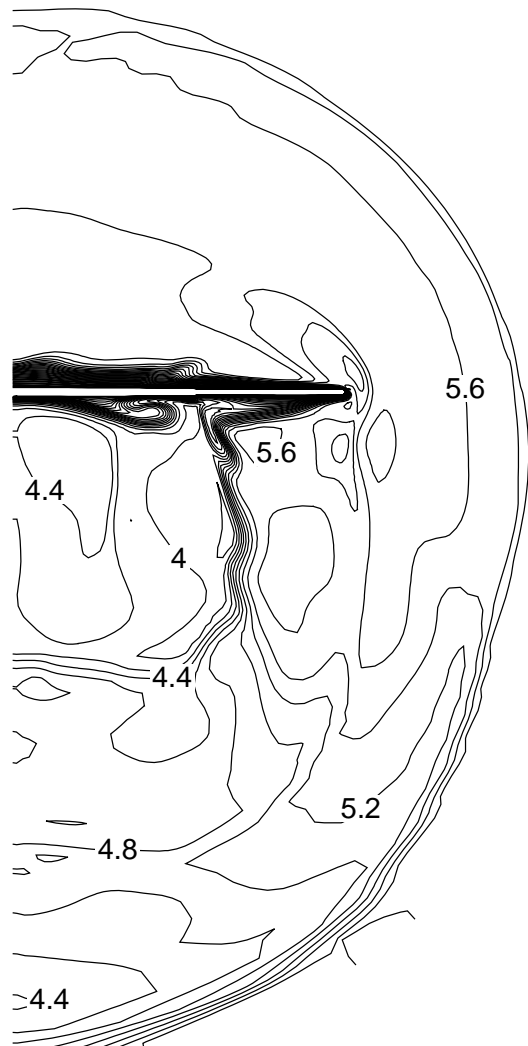

(c) Blocked-Off Inlet

Fig. 7. Mach number comparisons, body trailing edge, $M_{\infty}=5.92, N P R=200$. 


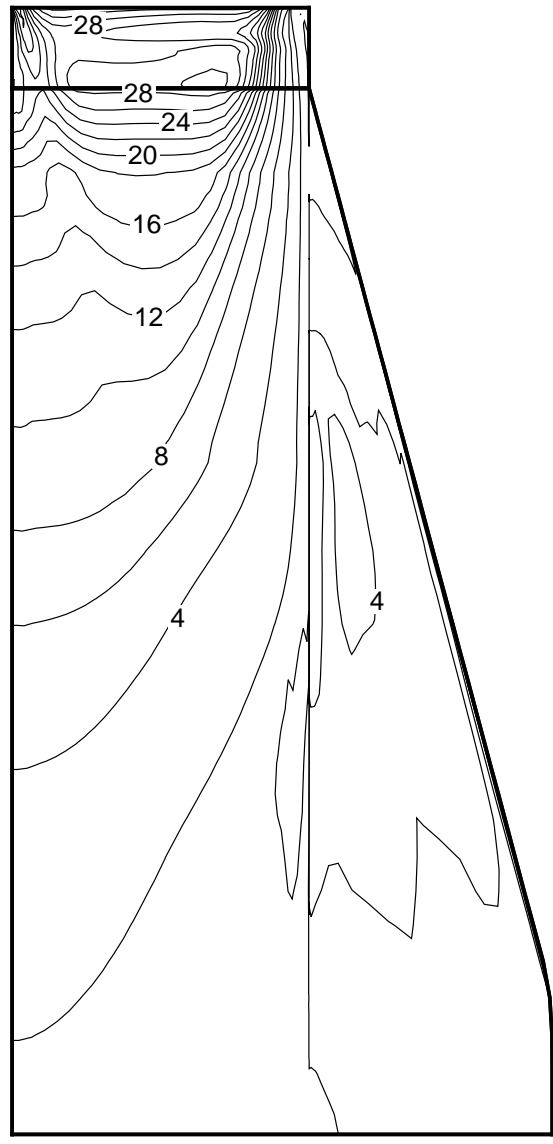

(a) Flow-Ingested Inlet

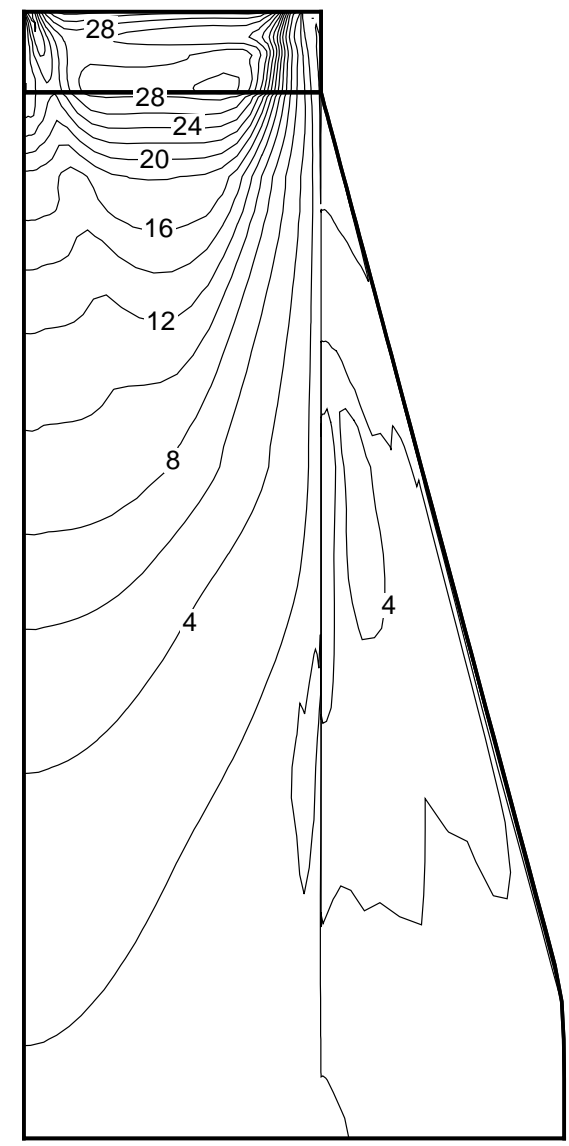

(b) Faired-Over Inlet

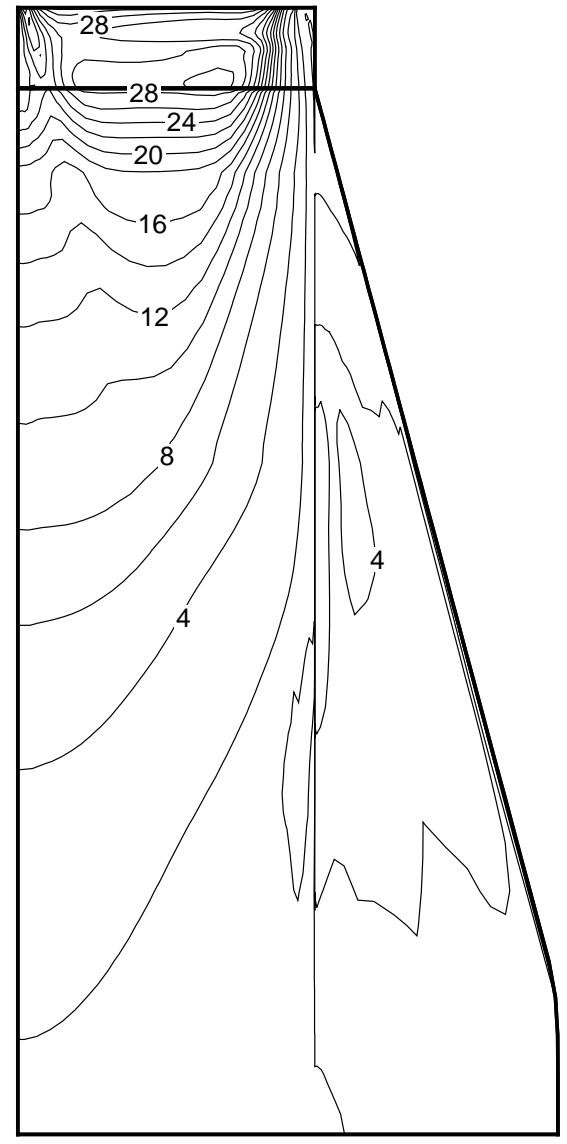

(c) Blocked-Off Inlet

Fig. 8. Aftbody lower surface pressure comparisons ( $p / p_{\infty}$ contours), $M_{\infty}=10.14, N P R=3,000$.

flow-ingested inlet cases are unity.

Figure 9a shows relative lift on the aftbody as a function of freestream Mach number. In terms of the fairing effects, the faired-over inlet solution provides lift values which are closer to the flow-ingested inlet solution at the two lower Mach numbers. At higher Mach numbers, the differences are negligible. Furthermore, the aerodynamic surface provides about 10 percent of the total lift on the aftbody.

In terms of aftbody relative thrust (Fig. 9b), the overall differences of the two closed-inlet solutions are small compared to the flow-ingested inlet solution, with the blockedinlet case showing slightly better agreement at the lower Mach numbers. For all three solutions at $\mathrm{M}_{\infty}=3.40$, the total aftbody thrust is negative, made up of two negative components. Therefore, the relative thrust is positive in this context. As freestream Mach number increases, the drag from the aerodynamic component becomes a small thrust, due to plume pressurization on the wing lower surface (which has a slightly negative incidence). As expected, the propulsive surface provides most of the aftbody thrust.

Figure 9c shows the relative pitching moment on the aftbody for the three forebody configurations of interest. The faired-over inlet case compares very well with the flowingested inlet case throughout the Mach number range. The large discrepancy in the blocked-off inlet case at $\mathrm{M}_{\infty}=5.92$ is due in part to the larger lift predicted there (see Fig. 9a).
Aside from the $\mathrm{M}_{\infty}=5.92$ condition, most of the pitching moment contribution is from the aerodynamic surfaces. Furthermore, these relative changes in pitching moment with increasing freestream Mach number are not trivial and not linear or smooth. In the region between $\mathrm{M}_{\infty}=4$ and $\mathrm{M}_{\infty}=8$, the external nozzle transitions from being highly overexpanded to highly underexpanded and causes large shifts in relative aerodynamic and propulsive forces and moments even without a fairing of any kind.

Based on comparisons of three-dimensional flowfield and aftbody force and moment data, the computational solutions presented show that for the most part, either closedinlet configuration may be satisfactory for determining downstream plume influences on powered-simulation models with metric aftbodies. If the entire model was metric, the cowl influences may be hard to separate and scale with Reynolds number on the blocked-off inlet case. As was seen two-dimensionally ${ }^{10}$, the plume tends to isolate the aftbody surface from the forebody flowfield differences. Those configurations that employ a soft fairing were shown to provide aftbody surface characteristics that are nearly identical with a model representation that would ingest the inlet flow. Thus, a faired-over inlet is a viable solution to one of the problems of small-scale hypersonic powered testing of airbreathing vehicles. 


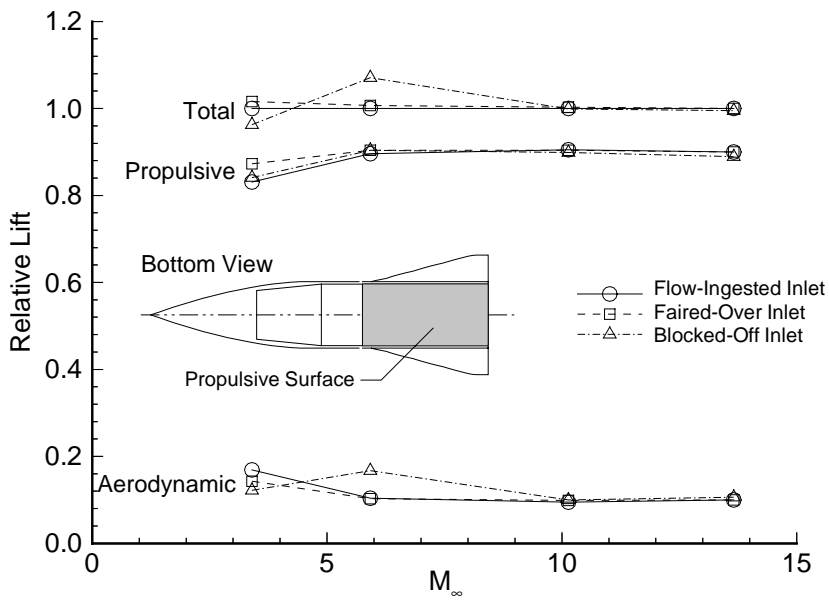

(a) Relative lift

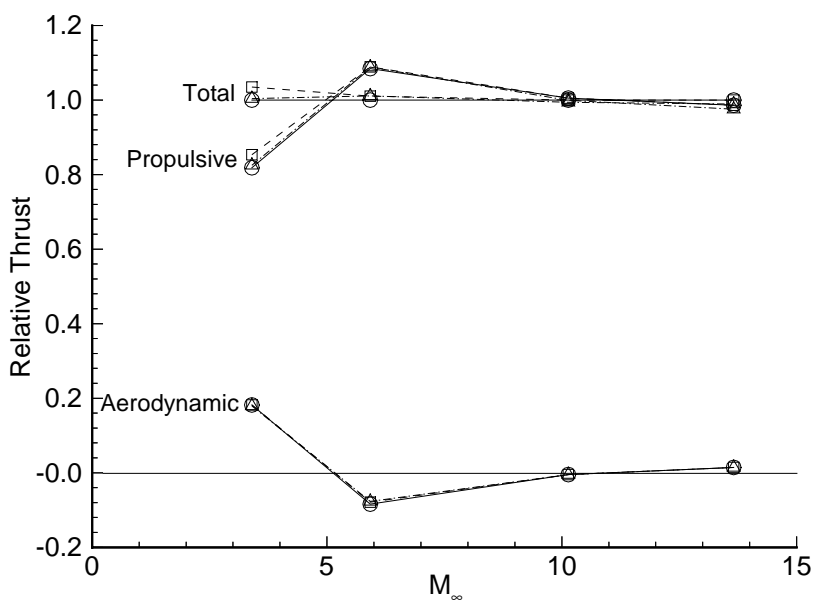

(a) Relative thrust

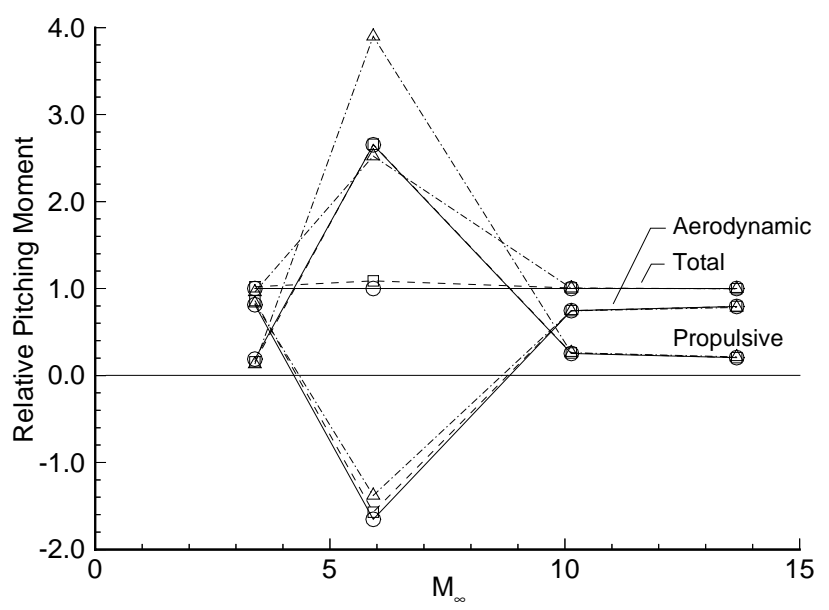

(a) Relative pitching moment

Fig. 9. Aftbody relative force and moment comparisons for flowing- and closed-inlet configurations.
Plume Characterization Results

In this section, the variation in plume extent will be presented for the flow-ingested (realistic) and faired-over inlet configurations. The wing impact of plume expansion will be discussed.

Figure 10 compares the plume boundaries for the flowingested and faired-over inlet configurations at three locations on the aftbody for the four Mach numbers of interest. Contour levels are drawn for 5-, 25-, 50-, 75-, and 95-percent exhaust mass fractions. Just beyond the cowl trailing edge (Fig. 10a) there is no significant difference in the shape of the plume boundary for the two configurations. The only difference is the increased diffusion of the plume boundary for the increasing freestream Mach number due to lower local freestream pressures. Midway down the aftbody (Fig. 10b), plume development has been established, and small differences now appear in comparing the two configurations. More importantly, the extent of the plume/body intersection is seen to be quite dependent on the physical conditions. For instance, at $\mathrm{M}_{\infty}=3.40, \mathrm{NPR}=30$, the plume remains completely on the external nozzle surface, whereas the $\mathrm{M}_{\infty}=13.66, \mathrm{NPR}=40,000$ solutions definitely show plume impingement on the wing. These trends continue downstream, as shown by the comparisons at the body trailing edge (Fig. 10c). The $\mathrm{M}_{\infty}=3.40$ plume is still confined to the aftbody lower surface and the $\mathrm{M}_{\infty}=13.66$ plume completely bathes the lower surface of the wing. The vertical extent of the plume boundaries is slightly less for the flow-ingested inlet cases, but the lateral and model-proximity characteristics are nearly identical.

\section{Summary}

Three studies have been presented addressing the computational capabilities of predicting complex three-dimensional hypersonic configuration flowfields under simulated powered conditions. The first study provided a level of confidence in the ability of a state-of-the-art CFD code to predict the surface pressure characteristics of this type of flow. It was shown that the lower-surface aftbody pressures were predicted quite well, whereas lower-surface wing pressures were less accurate, possibly requiring computation of the flows that include better prediction of separated flows.

Using this same code, a three-dimensional inlet representation study was performed which showed that a fairedover or blocked-off inlet causes only minor differences in the aftbody flowfield near the surface, surface pressures, and integrated forces and moments. Thus, this type of technique, when applied to hypersonic wind tunnel models testing under simulated powered conditions, can provide relatively accurate aftbody results.

Finally, results of the plume characterization for these types of powered flows at four increasing Mach number/ NPR conditions show a dramatic effect of plume expansion onto wing surfaces, probably causing pressurization and incremental changes in longitudinal force and moment values. 


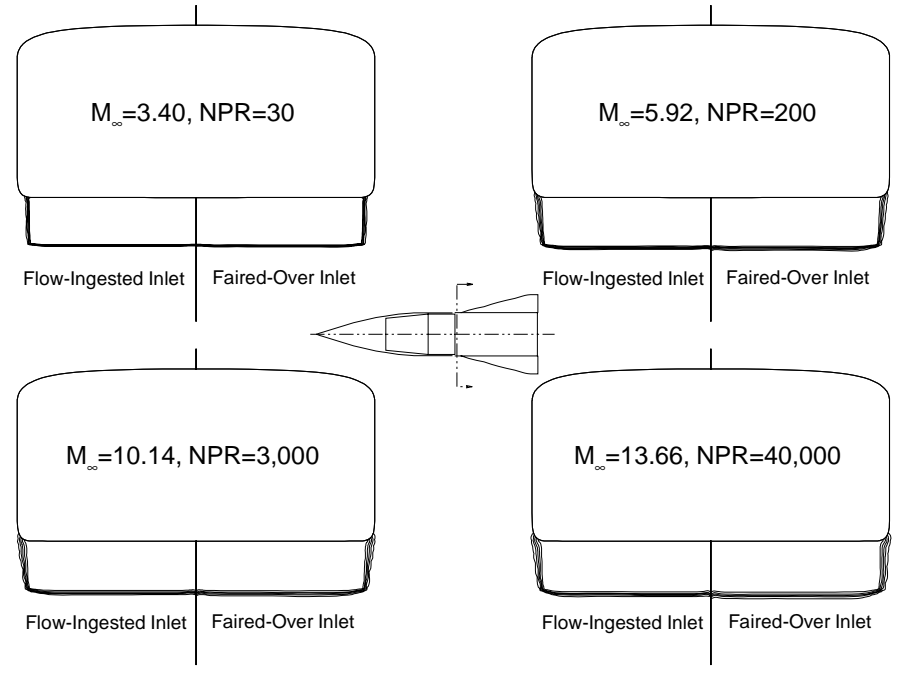

(a) just beyond cowl trailing edge

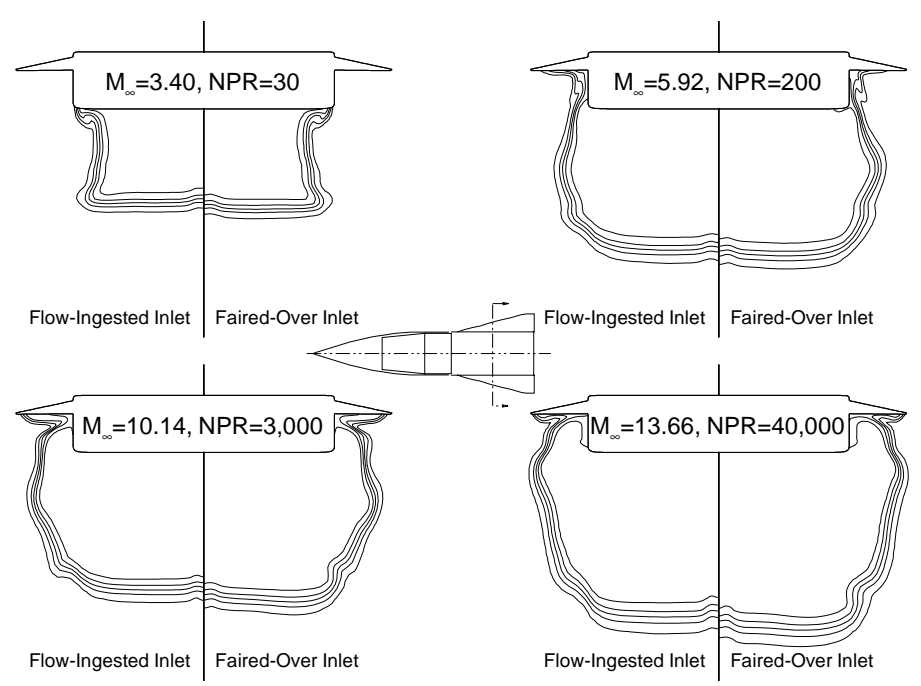

(b) midway down aftbody

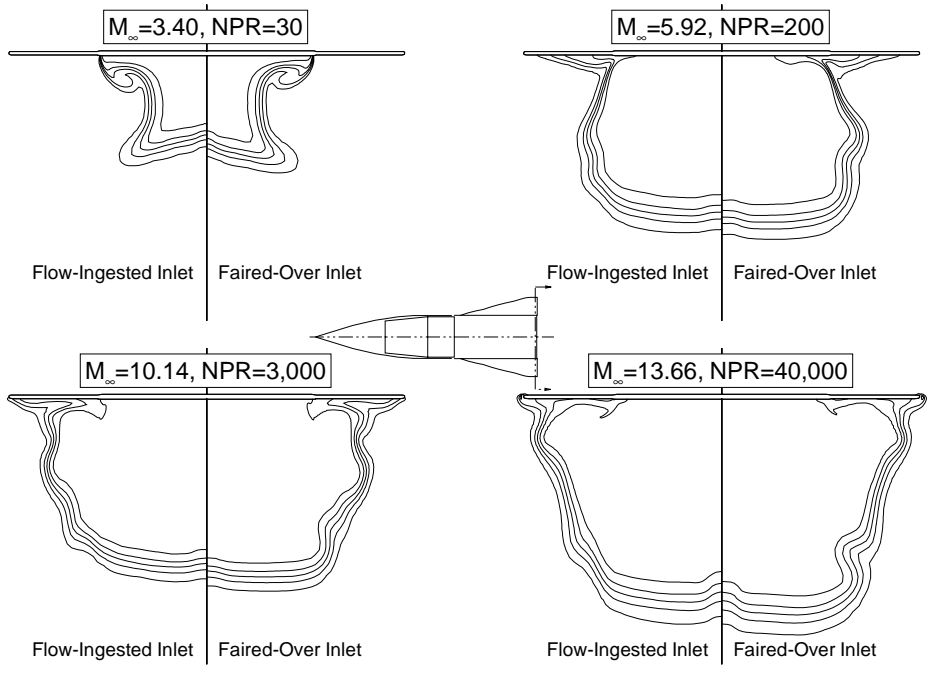

(c) body trailing edge

Fig. 10. Exhaust mass fraction contours, flow-ingested vs. faired-over inlet configurations. 


\section{$\underline{\text { References }}$}

1. Walters, R. W.; Slack, D. C.; Cinnella, P.; Applebaum, M.; and Frost, C.: A User's Guide to GASP, Revision 0. Virginia Polytechnic Institute \& State University, Department of Aerospace and Ocean Engineering and NASA Langley Research Center, November 1990.

2. McGrory, W. D.; Huebner, L. D.; Slack, D. C.; and Walters, R. W.: Development and Application of GASP 2.0. AIAA Paper 92-5067, December 1992.

3. Huebner, L. D., Pittman, J. L.; and Dilley, A. D.: Hypersonic Parabolized Naiver-Stokes Code Validation on a Sharp-Nose Cone, Journal of Aircraft, Vol. 26, No. 7, pp. 650-656.

4. Haynes, D. A.; Huebner, L. D.; and Blair, A. B., Jr.: Computational Refinement of the LaRC Test Technique Demonstrator Forebody with Experimental Verification. Sixth National Aero-Space Plane Technology Symposium, Paper No. 20, Monterey, CA, April 24-28, 1989, NASP CP-6034, Vol. I, pp. 27-46.

5. Huebner, L. D.: Computational Investigation of the LaRC Test Technique Demonstrator Reentry Configurations. Seventh National Aero-Space Plane Technology Symposium, Paper No. 36, Cleveland, OH, October 23-27, 1989, NASP CP-7040, Vol. I, pp. 153174.
6. Huebner, L. D.; and Tatum, K. E.: Computational and Experimental Aftbody Flowfields for Hypersonic, Airbreathing Configurations with Scramjet Exhaust Flow Simulation. AIAA Paper 91-1709, June 1991.

7. Tatum, K. E.; Monta, W. J.; Witte, D. W.; and Walters, R. W.: Analysis of Generic Scramjet External Nozzle Flowfields Employing Simulant Gases. AIAA Paper 90-5242, October 1990.

8. Witte, D. W.; Huebner, L. D.; and Monta, W. J.: Hypersonic Powered Aftbody Testing with a Simulant Exhaust at Mach 6. 1992 National Aero-Space Plane Mid-Term Technology Review, Paper No. 285 (Unclassified), Monterey, CA, April 21-24, 1992, NASP CP11067, Volume IV-Engine/Airframe Integration, pp. 257-280.

9. Richardson, P. F.; and Parlette, E. B.: Comparison Between Experimental and Numerical Results for a research Hypersonic Aircraft, Journal of Aircraft, Vol. 27, No. 4, pp. 300-305.

10. Huebner, L. D.; and Tatum, K. E.: Computational Effects of Inlet Representation on Powered Hypersonic, Airbreathing Models. Journal of Aircraft, (in press), expected publication issue, July-August 1993. 